Bull. Mater. Sci., Vol. 17, No. 6, November 1994, pp. 685-698. (C) Printed in India.

\title{
On the stress corrosion cracking mechanisms of austenitic stainless steels
}

\author{
P RODRIGUEZ, H S KHATAK and J B GNANAMOORTHY \\ Metallurgy and Materials Group, Indira Gandhi Centre for Atomic Research, \\ Kalpakkam 603 102, India
}

\begin{abstract}
In this paper, experimental results on stress corrosion cracking in austenitic stainless steels are described. Crack growth data in sodium chloride solution for AISI 304 steel obtained for different metallurgical conditions, acoustic emission data recorded during crack growth and fractographic observations have been discussed with a view to identifying the operating mechanism. Some of the experimental observations such as crack propagation occurring in discontinuous jumps of the order of a few microns, lowering of the threshold stress intensity and $J$-integral values on sensitization and cold working, typical transgranular fractographic features, transition in mode of fracture from transgranular to intergranular in sensitized conditions and activation energies of the order of 50 to $65 \mathrm{~kJ} / \mathrm{mol}$ can all be accounted by hydrogen embrittlement mechanism. Hydrogen generated at the crack tip by corrosion reaction diffuses ahead of the crack tip under hydrostatic stress and influences the deformation process at the crack tip and also leads to the brittle component of the crack advance in jumps.
\end{abstract}

Keywords. Austenitic stainless steel; stress corrosion cracking mechanism; acoustic emission; fractography; hydrogen embrittlement; transgranular and intergranular fracture.

\section{Introduction}

There are many similarities between stress corrosion cracking (SCC), hydrogen embrittlement (HE) and liquid metal embrittlement (LME). However, none of the suggested mechanisms seems to give a satisfactory explanation for the similarities found in these embrittlement phenomena. Different processes appear to operate under specific sets of metallurgical and environmental conditions. A successful study of environment-sensitive cracking requires an integrated interdisciplinary approach involving mechanics, chemistry and materials science. Fracture mechanics can provide a characterization of the phenomenology of cracking such as rate of crack advance and the associated crack velocity dependence on temperature, pressure and concentration of aggressive species in the environment. Surface chemistry and electrochemistry studies are needed to identify the rate limiting processes. Metallurgical investigations are important to identify the alloy compositions and microstructures that are susceptible to cracking as well as to understand the operative fracture micromechanisms. Currently two diametrically opposed view points exist: one school attributes crack propagation to the preferential dissolution of metal from a narrow region at the crack tip, while the other believes that brittle mechanical fracture is involved and is more important.

\section{Mechanisms of stress corrosion cracking}

The models which have been considered in the case of stress corrosion cracking in austenitic stainless steels are discussed below. 


\subsection{The slip dissolution model}

The unit process in the slip dissolution model (Champion 1948; Logan 1952; Staehle 1973) is the breaking of the passive film by egress of dislocations and the ensuing local transient dissolution of the metal followed by repassivation. The propagation of crack corresponds to a series of these events.

\subsection{A unified mechanism of SCC and corrosion fatigue}

In this model proposed by Jones (1985), anodic dissolution per se does not contribute to crack growth; vacancies formed at the site of anodic dissolution form divacancies which migrate to critical lattice sites and accumulate to cause brittle crack propagation; during corrosion fatigue cracking, divacancies may be formed also at internal vacancy sources from cyclic deformation.

\subsection{Hydrogen embrittlement (HE) model}

The phenomenon of stress corrosion cracking and hydrogen embrittlement have many similarities: in particular, both are characterized by an incubation time for crack initiation, discontinuous crack propagation and a threshold stress. The corrosion reaction at the crack tip is a source of hydrogen and plays a crucial role in SCC by providing the brittle component (Tien et al 1976; Hirth 1980).

\subsection{Surface mobility mechanism}

A mechanism based on surface mobility has been proposed by Galvele (1987, 1990). The mechanism has been developed assuming that crack will grow by arrival of surface vacancies to or emission of adatoms from the tip of crack. According to Rhead (1975), high surface mobility is produced by low melting point contaminants on the metal surface. Although the mechanism is speculative in nature, it accounts for many experimental observations and encompasses SCC, LME and HE in one mechanism.

\subsection{Other models}

Magnin et al (1990) proposed that in hardenable alloys for which the formation of junctions of dislocations and Lomer-Cottrell barriers is possible, localized enhancement of plasticity due to corrosion leads to dislocation pile ups. A brittle transgranular fracture by microcleavage promoted by restricted slip is then possible. The resultant stress relaxation can finally induce crack arrest because of intrinsic ductility of austenitic steels. Another recently proposed mechanism (Flanagan 1991) is that selective dissolution at the crack tip has the effect of lowering $K_{\mathrm{IC}}$ for cleavage. Crack propagation is discontinuous due to crack arrest by dislocation blunting. Renucleation involves active dissolution of slip planes at the crack tip which changes the stress state at critical Lomer-Cottrel locks causing them to fail by cleavage. 
In view of the ambiguity in the various mechanisms for explaining SCC in austenitic stainless steels, an attempt has been made to understand further the mechanism by combining fracture mechanics, acoustic emission, metallurgical and fractographic approaches in the present study.

\section{Experimental}

The material chosen for the investigation was a nuclear grade stainless steel AISI type 304 with a chemical composition of $\mathrm{C} 0.04 \%, \mathrm{Cr} 18.3 \%, \mathrm{Ni} 9.2 \%, \mathrm{Mn} \mathrm{1.65 \% ,}$ Si $0.37 \%$, S $0.003 \%, \mathrm{P} 0.023 \%, \mathrm{~N} 860 \mathrm{ppm}$, and balance Fe. The material was available in the form of plates of the size $5000 \times 2000 \times 15 \mathrm{~mm}$ in mill-annealed condition. The different treatments given to the mill-annealed material are listed in table 1 . Cold work was given by multipass rolling at room temperature.

The stress corrosion test samples were sub-size compact tension (CT) type with a width of $30 \mathrm{~mm}$ and thickness of $10 \mathrm{~mm}$ conforming to ASTM E-399 (1983). The specimens were machined such that the notch was parallel to the rolling direction. CT samples were precracked using a precracker (Model MTS 810 of Materials Test Systems, USA) at stress intensity factor $K_{\mathrm{I}}$ values (in mode I loading) in the range of 25 to $18 \mathrm{MPa} \cdot \mathrm{m}^{1 / 2}$. The crack was grown up to about $2.5 \mathrm{~mm}$.

For crack growth studies, an acidified sodium chloride solution of composition $5 \mathrm{M} \mathrm{NaCl}+0.15 \mathrm{M} \mathrm{Na} \mathrm{SO}_{4}+3 \mathrm{ml} / /$ of $\mathrm{HCl}$ was used. The $\mathrm{pH}$ of the solution at room temperature was 1.3 . The tests were conducted with the solution in boiling condition $(381 \mathrm{~K})$. To facilitate evaluation of activation energy of the cracking process, tests at two other temperatures $(363 \mathrm{~K}$ and $373 \mathrm{~K}$ ) were also carried out. Both increasing $K_{\mathrm{I}}$ (constant load) and decreasing $K_{\mathrm{I}}$ (wedge load) tests have been carried out. The average crack growth rates were determined by measuring the crack lengths on fracture surfaces using nine-point average method. The increasing $K_{\mathrm{I}}$ tests were used to generate data for crack growth rates $>1 \times 10^{-9} \mathrm{~ms}^{-1}$. The crack growth rates of less than $1 \times 10^{-10} \mathrm{~ms}^{-1}$ were generated using wedge loaded samples.

Acoustic signals during crack growth were recorded using an equipment from Acoustic Emission Corporation, USA, model 204B with preamplifier 140B. Detailed fractographic examinations were carried out using both optical and scanning electron microscope. The crack growth analysis was carried out using the fracture mechanics parameters viz. stress intensity factor $K_{1}$ and $J$-integral $J_{1}$ described respectively in ASTM standards E 399-83 (1983) and E 813-81 (1981).

Table 1. Material treatments.

Solution annealed $(1323 \mathrm{~K}, 1 \mathrm{~h})$
Sensitization $(923 \mathrm{~K}, 20 \mathrm{~h})$
Cold working $(10 \%$ reduction in thickness)
Cold working $(20 \%$ reduction in thickness)
Cold working $(10 \%)+$ sensitization $(923 \mathrm{~K}, 20 \mathrm{~h})$
Cold working $(20 \%)+$ sensitization $(923 \mathrm{~K}, 20 \mathrm{~h})$




\section{Results}

\subsection{Crack growth data}

The results obtained on solution annealed and sensitized materials are plotted against the parameters $K_{1}$ and $J_{1}$ respectively in figures 1 and 2 . The shapes of the curves look similar; there is a threshold $K_{\mathrm{I}}$ or $J_{\mathrm{I}}$ (the threshold values were obtained from wedge loaded, constant displacement tests); above the respective threshold values large increase in crack growth rates takes place and then reaches a plateau region. Sensitization reduced the threshold values and increased the plateau crack growth rates. The shapes of the curves for other metallurgical conditions looked similar. The crack growth data for all the metallurgical conditions are summarized in table 2. The threshold values were found to be lower for the cold worked condition than those for sensitized and solution annealed conditions. The plateau velocities, however, were also lower (in the cold worked condition). Sensitization of cold worked material showed slightly improved threshold values but with larger crack growth rates in the plateau. Influence of cold work is overshadowed by the effects of sensitization. The maximum crack growth rate in $20 \%$ cold worked + sensitized material was found to be the same as that for solution annealed material. However, threshold value was lower.

\subsection{Results of activation energy measurements}

Figure 3 shows Arrhenius plots of crack growth rate vs $1 / T$ for solution annealed,

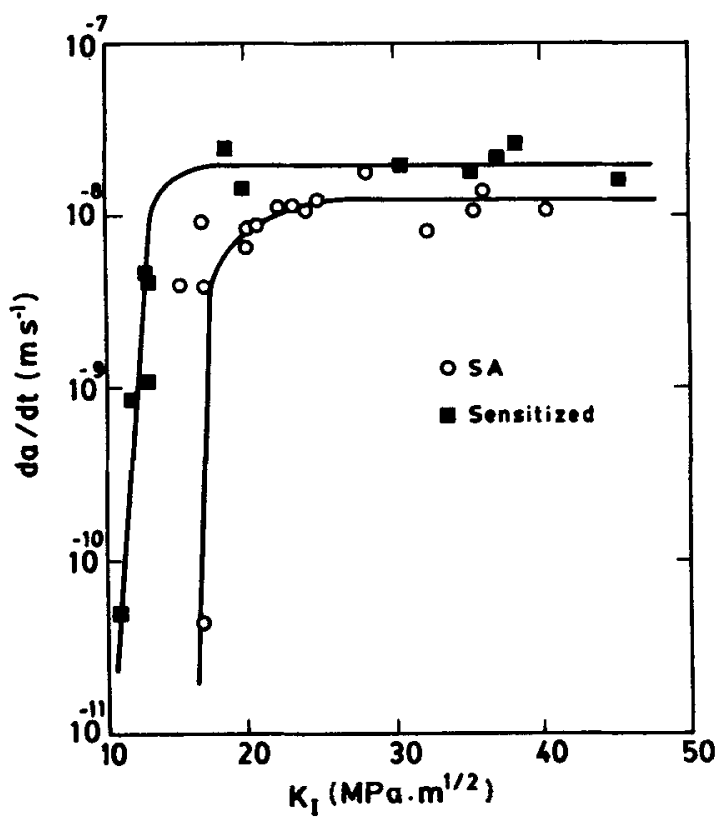

Figure 1. Influence of sensitization crack growth rate of AISI 304 stainless steel as a function of stress intensity factor in $5 \mathrm{M}+0.15 \mathrm{M} \mathrm{Na} \mathrm{SO}_{4}+3 \mathrm{ml} / 1 \mathrm{HCl}$ at $381 \mathrm{~K}$. 


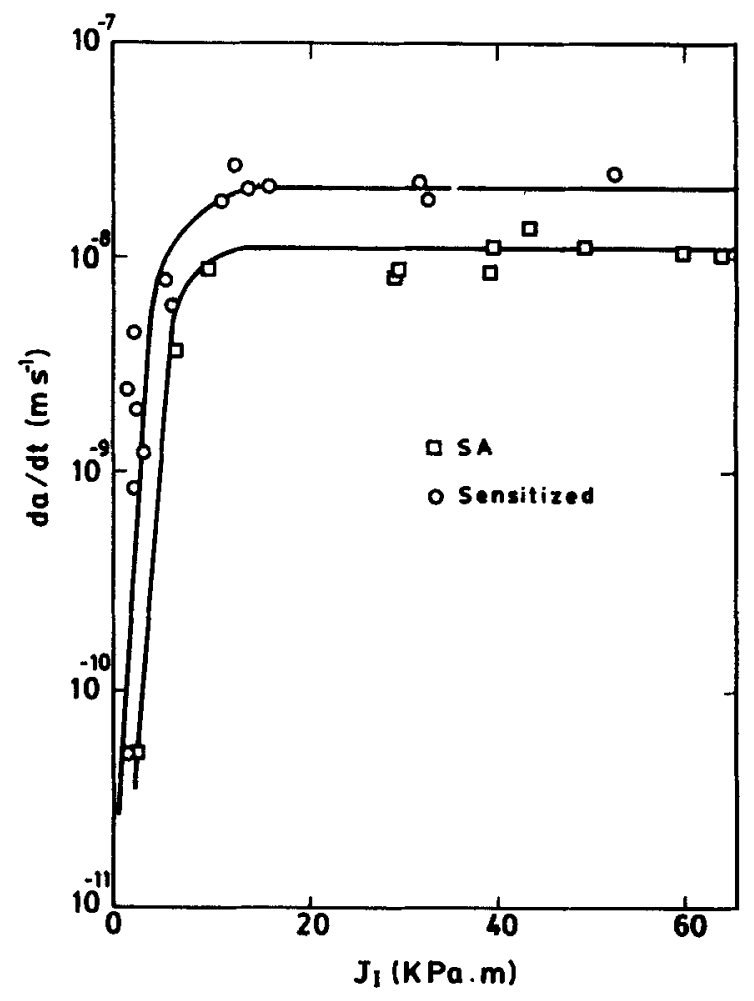

Figure 2. Influence of sensitization on crack growth rate of AISI 304 stainless steel as a function of $J$-integral in $5 \mathrm{M}+0.15 \mathrm{M} \mathrm{Na} \mathrm{SO}_{4}+3 \mathrm{ml} / \mathrm{HCl}$ at $381 \mathrm{~K}$.

Table 2. Summary of crack growth data.

\begin{tabular}{lccc}
\hline Material condition & $\begin{array}{c}K_{\text {Iscc }} \\
\left(\mathrm{MPa} \mathrm{m}^{1 / 2}\right)\end{array}$ & $\begin{array}{c}\text { Kscc } \\
\left(\mathrm{KPa}^{\mathrm{m}}\right)\end{array}$ & $\begin{array}{c}\text { da/dt } \\
(\mathrm{plateau}) \\
\left(\mathrm{ms}^{-1}\right)\end{array}$ \\
\hline SA & 17 & 0.9 & $1.3 \times 10^{-8}$ \\
Sensitized & 11 & 0.5 & $2.3 \times 10^{-8}$ \\
$10 \% \mathrm{CW}$ & 9 & 0.45 & $4 \times 10^{-9}$ \\
$20 \% \mathrm{CW}$ & 3 & 0.15 & $8 \times 10^{-9}$ \\
$10 \% \mathrm{CW}+$ sensitized & 8 & 0.37 & $2.3 \times 10^{-8}$ \\
$20 \% \mathrm{CW}+$ sensitized & 7 & 0.25 & $1 \times 10^{-8}$ \\
\hline
\end{tabular}

SA, solution annealed; CW, cold worked.

sensitized and $10 \%$ cold worked conditions. Values of activation energies evaluated from these plots are in the range $50-65 \mathrm{~kJ} / \mathrm{mol}$. 


\subsection{Results of acoustic emission}

Acoustic events were measured for solution annealed, sensitized and $10 \%$ cold worked materials. The number of acoustic events was found to vary linearly with time in all the cases. A typical record of background noise level and acoustic signal for a solution annealed material is shown in figure 4 . Time period per event

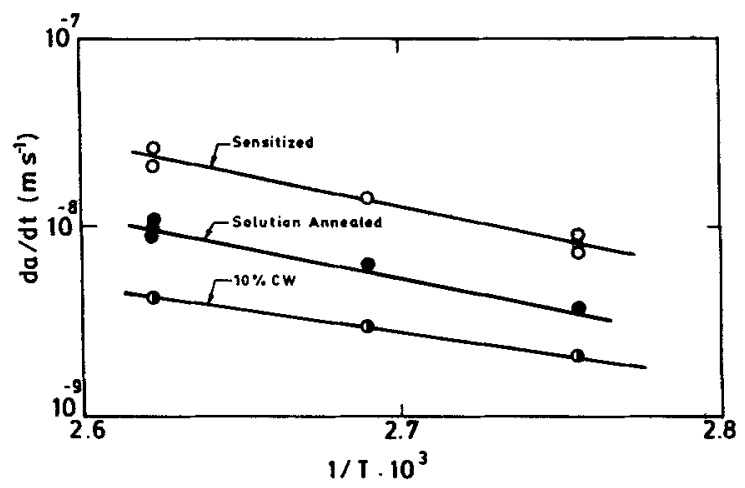

Figure 3. Variation of crack growth rate with temperature for AISI 304 stainless steel in solution annealed, sensitized and $10 \%$ cold worked condition in $5 \mathrm{M}+0.15 \mathrm{M} \mathrm{Na2} \mathrm{SO}_{4}+$ $3 \mathrm{ml} / 1 \mathrm{HCl}$.

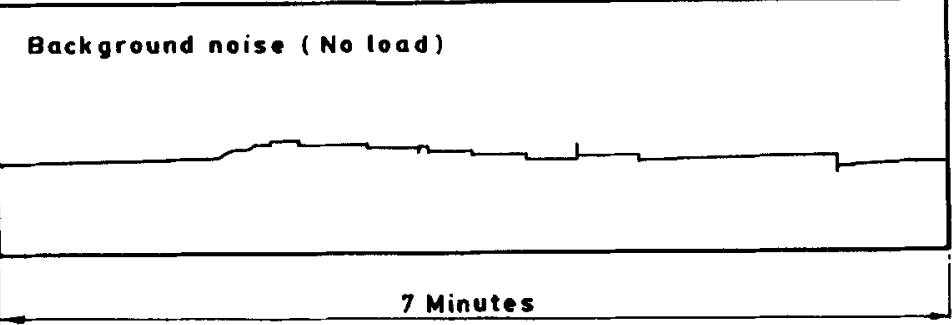

(a)

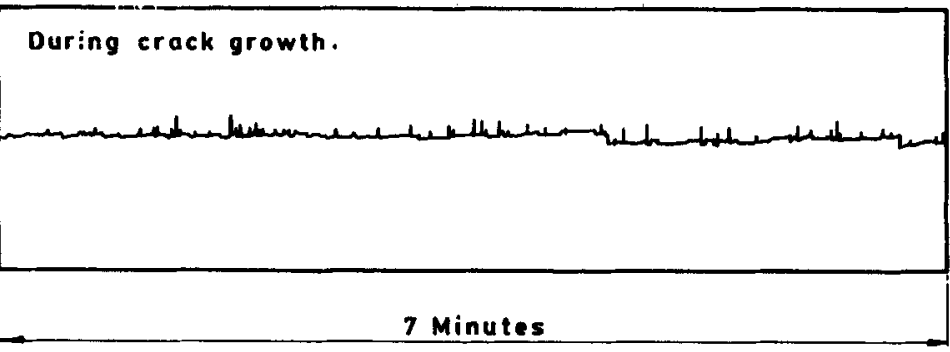

(b)

Figure 4. Typical record of acoustic events for 304 stainless steel in solution annealed condition during crack growth in $5 \mathrm{M}+0.15 \mathrm{M} \mathrm{Na}_{2} \mathrm{SO}_{4}+3 \mathrm{ml} / \mathrm{HCl}$. 
and crack growth per event computed from acoustic emission and crack growth data are presented in table 3 . The crack growth per event varies from less than a micron for a solution annealed material to $15 \mu \mathrm{m}$ for $10 \%$ cold worked material.

\subsection{Fractographic observations}

4.4a Solution annealed material: Mode of fracture was found to be transgranular type irrespective of stress levels. A typical fan-shaped pattern was seen which was not very clear at initiation. Crystallographic pits, secondary cracking and serration on river lines were also seen. Figure 5a shows river lines on well developed fan pattern. A number of parallel lines/cracks perpendicular to river lines are also seen (figure 5b).

$4.4 \mathrm{~b}$ Cold worked material: The fractographic features observed in 10 and $20 \%$ cold worked materials were similar to those seen on fracture surfaces of solution annealed material. Density of fan-shaped pattern was found to be higher in cold worked condition. Fans were not clearly delineated at the beginning and at the end of crack.

4.4c Solution annealed + sensitized material: The crack initiation was always in transgranular mode irrespective of test method and stress levels. Also, the propagation along the edges was transgranular. However, there was a transition in the mode of fracture to intergranular in the mid thickness region. Figures $6 a$ and $b$ show different stages of crack propagation along the central line of the specimen. The transition from transgranular to intergranular is seen in figure $6 \mathrm{a}$ whereas in figure $6 \mathrm{~b}$ fully intergranular fracture is seen. The transgranular fracture surface near the

Table 3. Acoustic emission data obtained during crack growth.

\begin{tabular}{|c|c|c|c|c|c|c|}
\hline \multirow[b]{2}{*}{ Condition } & \multicolumn{2}{|c|}{ Range } & \multirow[b]{2}{*}{$\begin{array}{c}\Delta a-S C C \\
(\mathrm{~mm})\end{array}$} & \multirow[b]{2}{*}{$\begin{array}{c}\mathrm{d} a / \mathrm{d} t \\
\left(\mathrm{~ms}^{-1}\right)\end{array}$} & \multirow[b]{2}{*}{$\begin{array}{c}\mathrm{d} a d \mathrm{~d} N \\
(\mu \mathrm{m} / \mathrm{N})\end{array}$} & \multirow{2}{*}{$\begin{array}{c}\text { Time period } \\
\text { per event } \\
\text { (sec) }\end{array}$} \\
\hline & $\begin{array}{c}K_{\mathrm{I}} \\
\left(\mathrm{MPam}^{1 / 2}\right)\end{array}$ & $\begin{array}{c}J_{1} \\
\text { (KPa.m) }\end{array}$ & & & & \\
\hline SA & $33-46$ & $9 \cdot 7-70$ & 1.85 & $1.10 \times 10^{-8}$ & 0.55 & 50 \\
\hline SA & $24-30$ & $65-130$ & 1.65 & $1.60 \times 10^{-8}$ & 1.15 & 72 \\
\hline SA & $27-33$ & $10-13$ & 1.86 & $7.7 \times 10^{-9}$ & 6.35 & 1716 \\
\hline $\begin{array}{r}\text { SA + sensitized } \\
\quad(923 \mathrm{~K}, 20 \mathrm{~h})\end{array}$ & $15-25$ & $1-6 \cdot 5$ & $2 \cdot 90$ & $8.6 \times 10^{-9}$ & $2 \cdot 30$ & 375 \\
\hline $10 \% \mathrm{CW}$ & $18-20$ & $2 \cdot 6-5$ & 0.66 & $7 \times 10^{-10}$ & 0.27 & 380 \\
\hline $10 \% \mathrm{CW}$ & $43-80$ & $15-107$ & $5 \cdot 32$ & $4.8 \times 10^{-9}$ & 15 & 2870 \\
\hline $10 \% \mathrm{CW}$ & $24-43$ & $6 \cdot 7-27$ & 3.70 & $3.6 \times 10^{-9}$ & 11 & 3120 \\
\hline $\begin{array}{l}10 \% \mathrm{CW}+ \\
\text { sensitized } \\
(923 \mathrm{~K}, 20 \mathrm{~h})\end{array}$ & $18-23$ & $0 \cdot 5-11$ & 6.4 & $6.8 \times 10^{-9}$ & 2 & 293 \\
\hline $\begin{array}{l}10 \% \mathrm{CW}+ \\
\text { sensitized } \\
(923 \mathrm{~K}, 20 \mathrm{~h})\end{array}$ & $17-27$ & $1 \cdot 5-419$ & 10 & $1.7 \times 10^{-8}$ & 10 & 514 \\
\hline
\end{tabular}

SA, solution annealed: $\mathrm{CW}$, cold worked. 

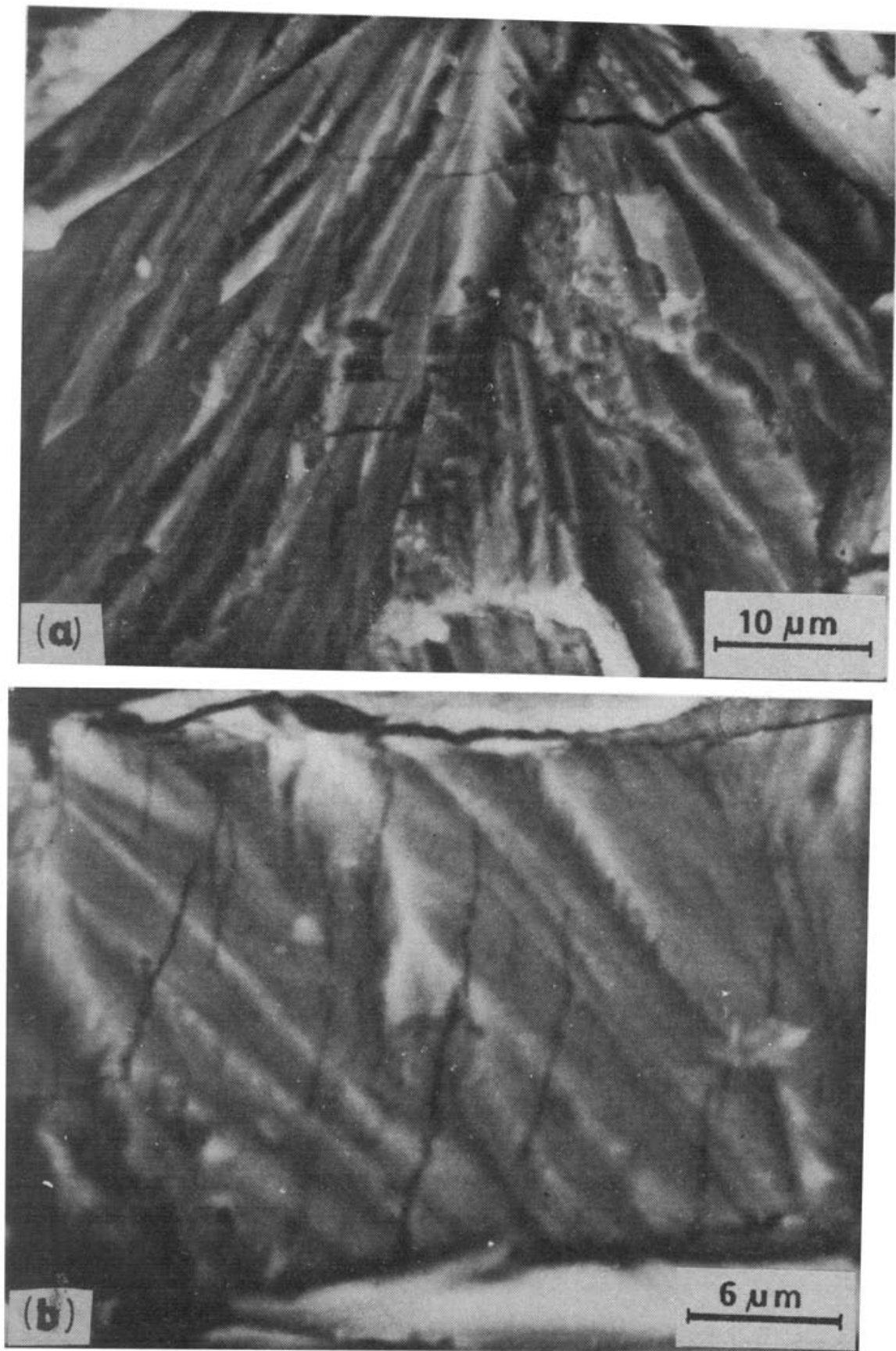

Figure 5. Scanning clectron tuscroscope fractograph of soluton annealed AISI 304 stainless steel showing (a) river lines and (b) crack arrest lines. 

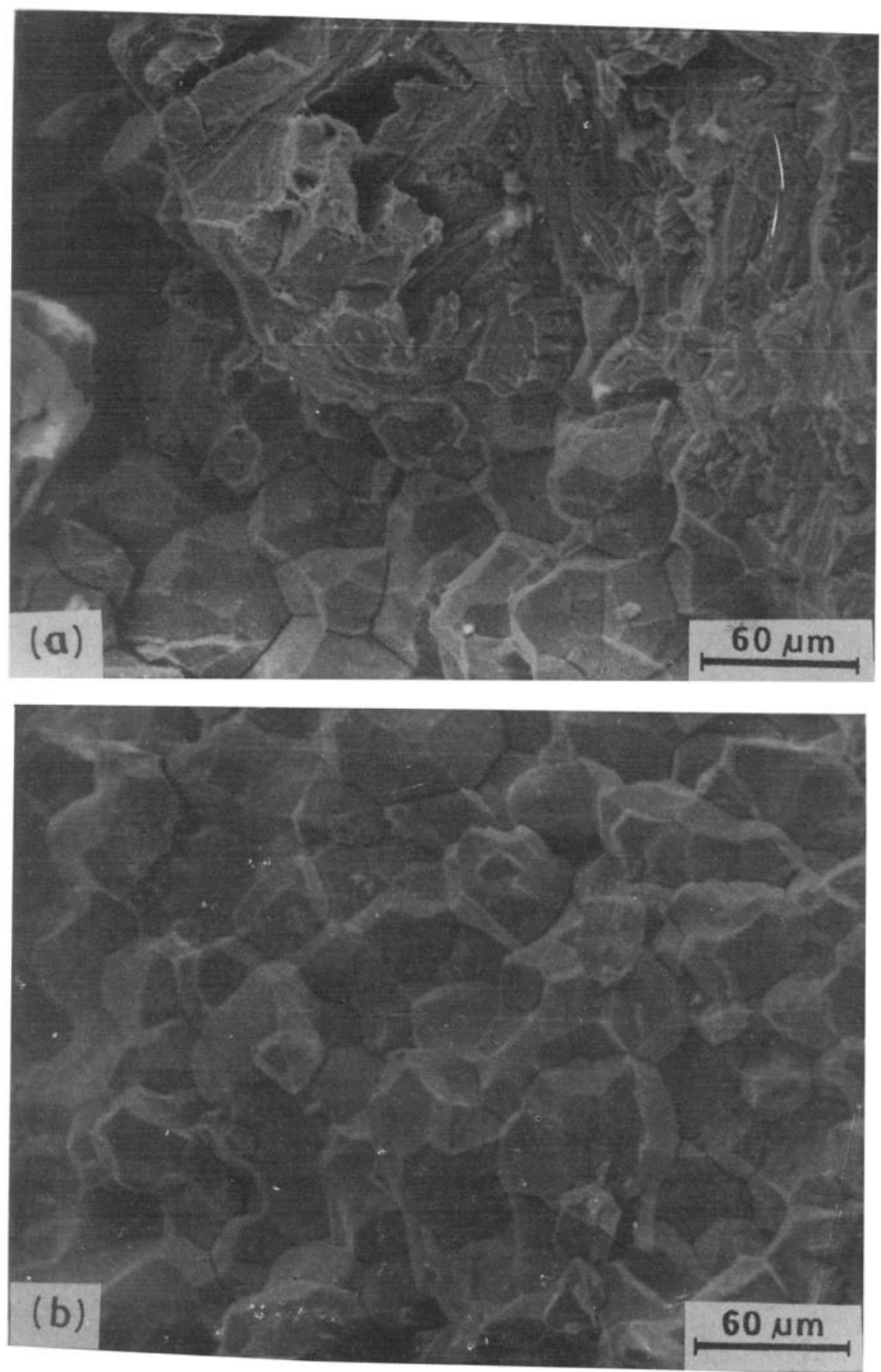

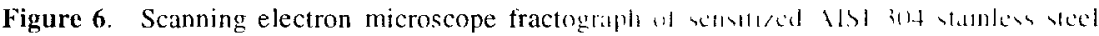
showing (a) initiation as transgranulu. Ahunges (1) intergranular and (b) complete intergranular. 
edge showed serrations or markings (parallel lines) perpendicular to the river lines (figure 7a). These serrations, almost parallel to one another, are crack arrest markings. Deep grain boundary grooving and dissolution of the matrix at localized spots were observed at surfaces perpendicular to the fracture surface (figure $7 \mathrm{~b}$ ).

4.4d Sensitized material with prior cold work: Specimens with $10 \%$ cold work + sensitization showed features similar to those without cold work. In the case of $20 \%$ cold work + sensitized samples, the crack initiation was in mixed mode (transgranular + intergranular) unlike transgranular initiation in all the other cases.

4.4e Tests at lower temperatures: Solution annealed, solution annealed + sensitized, and $10 \%$ cold worked samples tested at $373 \mathrm{~K}$ showed similar fractographic features as those tested at $381 \mathrm{~K}$. When the test temperature was further decreased to 363 $K$, the sensitized specimens showed mainly intergranular fracture including at the initiation point.

\section{Discussion}

The mechanism suggested for SCC of austenitic stainless steels should account for the following experimental observations in the present investigations:

(i) Existence of a plateau region on crack growth curve.

(ii) Plateau crack growth rate of the order of $10^{-8} \mathrm{~ms}^{-1}$ for solution annealed material.

(iii) Increase in crack growth rate on sensitization and decrease on cold working.

(iv) Existence of threshold $K_{\text {ISCC }}$ or $J_{\text {ISCC }}$ and their decrease on sensitization and cold working.

(v) Matching of fracture surfaces.

(vi) Transgranular fracture features like river lines, fan-shaped pattern, serrations and striations seen on the fracture surface.

(vii) Discontinuous mode of fracture as revealed by acoustic emission and crack arrest marks on the fracture surfaces.

(viii) Transition in mode of fracture in the case of sensitized material.

(ix) Activation energy of 50 to $65 \mathrm{~kJ} / \mathrm{mol}$.

The various mechanisms reviewed in $\S 2$ will be discussed in the light of the observations in this investigation. It is generally agreed that stress corrosion phenomenon involves not only the generation of a new surface by plastic flow but is also sensitive to the rate at which the surface is generated. Stress corrosion is regarded as a balance between the dissolution rate and the rate of creation of new surface (Scully 1968; Staehle et al 1969). However, metal dissolution is considered as the rate controlling factor. Based on this mechanism, existence of a threshold stress, plateau region, transition in mode of fracture, higher crack growth rates in sensitized material and matching fracture surfaces can be explained. But the model cannot account for the discontinuous mode of fracture and many of the fracture features. The role of stress is considered only in the generation of new surfaces; but dissolution alone cannot account for such high crack growth rates of the order of $10^{-8} \mathrm{~ms}^{-1}$. Also it is known that cold working results in increase in dissolution rate (Stefec and Franz 1978). If dissolution was rate controlling, one would expect 

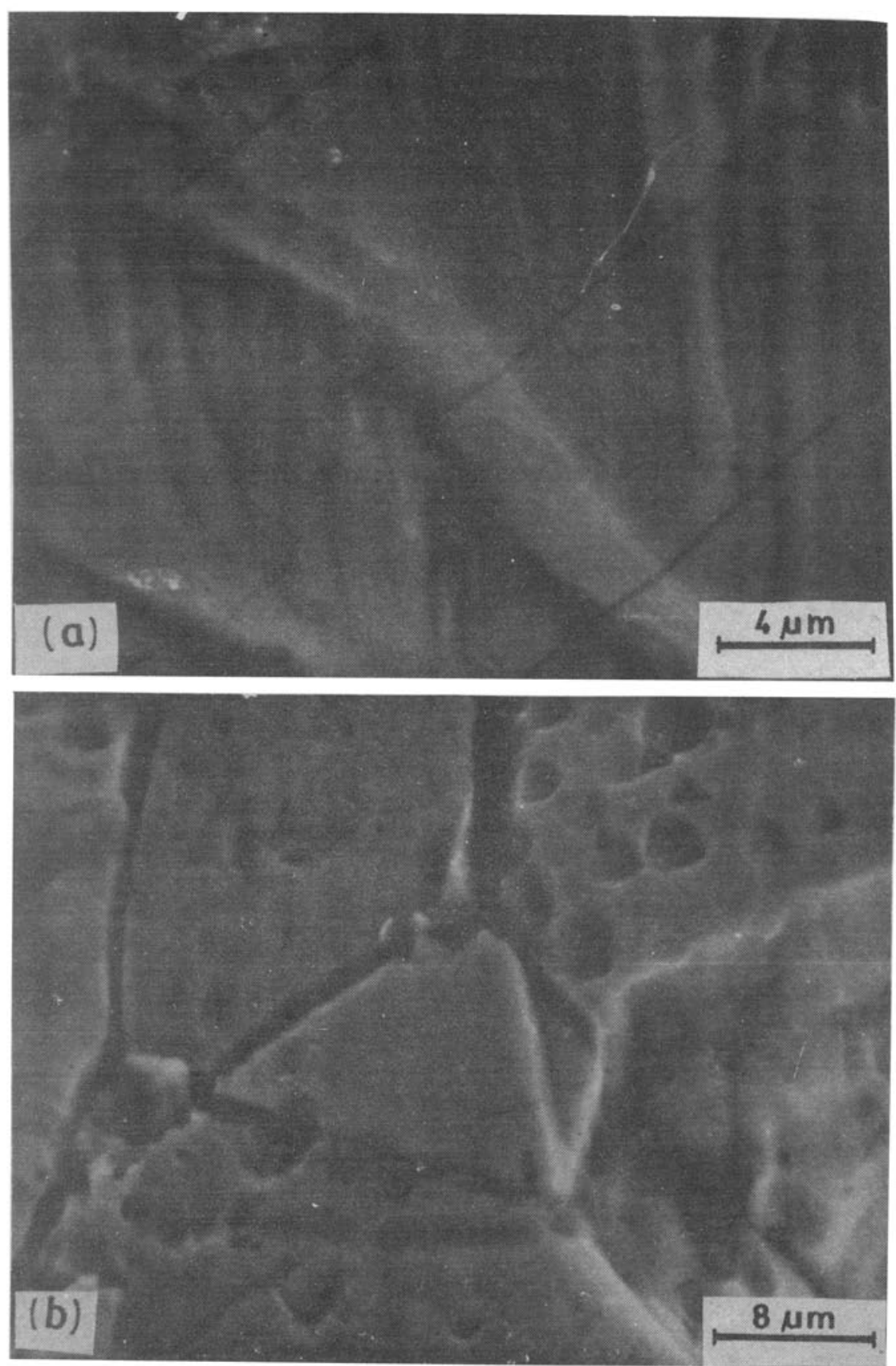

Figure 7. Scanning electron microscope of sensitized AISI 304 stainless steel showing (a) crack arrest marks and (b) dissolution on surface perpendicular to fracture surface. 
increase in crack growth rate on cold working, which is contrary to the present observation (table 2). However, the mechanism can explain the decrease in threshold stress values on cold working.

As far as the surface mobility mechanism is concerned, assuming that $\mathrm{CrCl}_{2}$ (melting point $1097 \mathrm{~K}$ ) is formed, the crack growth rates were calculated using the procedure given by Galvele (1987). Stress levels equal to that of yield strength were assumed to be present at the crack tip; in the plateau region, the crack tip stress will be of this magnitude. The crack growth rates thus calculated for a test temperature of $381 \mathrm{~K}$ are shown in table 4 and compared with the experimentally measured crack growth rates. It is seen that the crack growth rates predicted are much higher than the observed ones. If the compounds formed at the crack tip are assumed to be iron halides with lower melting points, the predicted crack growth rates would be still higher. Thus surface mobility mechanism predicts increase in crack growth rates with cold work which is also not in conformity with the present observations. The fractographic features and the discontinuous crack propagation also cannot be explained. A further objection to this mechanism is that it is speculative as the assumptions involved cannot be verified.

A brittle component along with anodic dissolution has been proposed by many authors (Jones 1985; Dickson et al 1987; Magnin et al 1990; Flanagan 1991). In the unified mechanism of Jones (1985), the brittle crack propagation takes place by cleavage-like fracture due to the accumulation of divacancies ahead of the crack tip. The root mean distance $R$ that the divacancies can diffuse ahead of the crack tip is given by

$$
R=2.45(D t)^{1 / 2}
$$

taking $t$ as the time per crack growth event (table 5) from the acoustic emission data and a value for $D=10^{-12} \mathrm{~cm}^{2} / \mathrm{sec}$ (Louthan and Devrick 1975). The distance $R$ which is equal to the crack growth per event was calculated for solution annealed, sensitized and $10 \%$ cold worked materials. These were found to be $0.2,0.5$ and $1.3 \mu \mathrm{m}$ respectively. Crack arrest markings (1 to $7 \mu \mathrm{m}$ on fractographs, figures $5 \mathrm{~b}$ and 7a) and crack growth per acoustic event of less than a micron to $15 \mu \mathrm{m}$ (table 5) show that crack growth per jump is of the order of a few microns. This is in the range of $R$ values calculated above. Since both corrosion and brittle components are considered, high -crack growth rate, change of propagation rate with structural changes, influence of temperature and fractographic features can be explained. Another point supporting the divacancy mechanism is that the measured activation energy for SCC appears to be of the right magnitude estimated for divacancy migration energy in austenitic stainless steel. However, it must be commented that for the divacancy mechanism cold working should have enhanced the crack growth which was not observed. The interesting point is that activation energy for hydrogen diffusion in austenitic steels is also of the same magnitude. Hydrogen diffusion distances per event time for plateau region of crack growth curves calculated using

$$
X=(D t)^{1 / 2}
$$

given by Louthan and Devrick (1975) are also presented in table 5 along with the acoustic emission data. A diffusion coefficient of $1.76 \times 10^{-10} \mathrm{~cm}^{2} / \mathrm{sec}$ for hydrogen 
Table 4. Crack growth rates calculated using the equation given by Galvele (1987) (Test temperature $381 \mathrm{~K}$ ).

\begin{tabular}{lcc}
\hline Material condition & $\begin{array}{r}\text { Crack growth rate }\left(\mathrm{ms}^{-1}\right) \\
\text { (calculated) }\end{array}$ & $\begin{array}{c}\text { Crack growth rate } \\
\text { (measured) }\end{array}$ \\
\hline Solution annealed & $7.6 \times 10^{-7}$ & $1.3 \times 10^{-8}$ \\
Sensitized & $7 \times 10^{-7}$ & $2.3 \times 10^{-8}$ \\
$10 \%$ Cold worked & $2.6 \times 10^{-6}$ & $4 \times 10^{-9}$ \\
$20 \%$ Cold worked & $3.7 \times 10^{-6}$ & $8 \times 10^{-9}$ \\
$10 \%$ Cold worked + & $1.8 \times 10^{-6}$ & $2.3 \times 10^{-8}$ \\
sensitized & $3.1 \times 10^{-6}$ & $1 \times 10^{-8}$ \\
$20 \%$ Cold worked + & & \\
sensitized & & \\
\hline
\end{tabular}

Table 5. Acoustic data in $K_{[- \text {-independent region. }}$

\begin{tabular}{lcccc}
\hline $\begin{array}{l}\text { Material } \\
\text { condition }\end{array}$ & $\begin{array}{c}K_{1} \text { range } \\
\left(\mathrm{MPa} . \mathrm{m}^{1 / 2}\right)\end{array}$ & $\begin{array}{c}\text { Average time } \\
\text { period/event } \\
(\mathrm{sec})\end{array}$ & $\begin{array}{c}\Delta a / N \\
(\mu \mathrm{m} / \mathrm{event})\end{array}$ & $\begin{array}{c}\text { Hydrogen } \\
\text { diffusion distance } \\
(\mu \mathrm{m} / \text { event })\end{array}$ \\
\hline SA & $33-46$ & 50 & 0.55 & 13 \\
SA & $24-30$ & 72 & 1.15 & 159 \\
Sensitized & $15-25$ & 375 & 2.30 & 360 \\
$10 \% \mathrm{CW}$ & 43.80 & 2870 & 15.00 & 1000 \\
$10 \% \mathrm{CW}$ & $24-43$ & 3120 & 11.00 & 1040 \\
\hline
\end{tabular}

$\mathrm{SA}$, solution annealed; CW, cold worked.

diffusion in austenitic stainless steels measured by the same authors was used. It is seen that during the time between crack events hydrogen can diffuse to a distance higher than the measured crack growth per event. This is a reasonable result, since crack growth by cleavage will take place only in the region ahead of crack tip where sufficient hydrogen concentration has been built up and not through the whole length of the plane to which hydrogen has diffused. Cold work does not influence the diffusivity of hydrogen significantly (Louthan and Devrick 1975). The lower crack growth rate observed in cold worked material is attributed to the increase in strength on cold working. In a stronger material crack tip opening will be restricted. The supply of corrosive environment at the tip also will be less, resulting in reduced corrosion and hence less hydrogen availability. Fractographic features (transgranular) are similar to microcleavage caused by hydrogen. Sensitized material has mostly shown intergranular failure which is similar to the observations of Briant (1978) in hydrogen gas. Role of hydrogen in crack propagation through reduction in stacking fault energy (SFE) at crack tip has also been recently reported (Jani 1991). Hydrogen is the only environmental species which is capable of reducing SFE of austenitic steels. Most of the observations in the present investigation could be accounted for by hydrogen embrittlement model. 


\section{Conclusions}

The main observations on the crack growth data obtained on AISI 304 steel in acidified sodium chloride solution (b.p. $381 \mathrm{~K}$ ) are summarized below:

(i) Crack growth rates of the order of $1 \times 10^{-8} \mathrm{~m} / \mathrm{s}$ were observed for solution annealed material. Threshold parameters were found to decrease on sensitization and cold working. Sensitization and tests at lower temperature enhanced the probability of intergranular fracture.

(ii) Fractographic features and acoustic emission data indicated discontinuous mode of fracture.

(iii) Activation energies for the crack growth process were measured to be in the range of 50 to $65 \mathrm{~kJ} / \mathrm{mol}$.

These results have been discussed in the light of different mechanisms. The mechanism involving the role of hydrogen (produced due to corrosion reaction at the crack tip) in the brittle component of crack jumps is able to account for most of the observations in the present investigations.

\section{References}

American Society for Testing Materials 1983 Designation E 399-83, 1981 designation E 813-81

Briant C L 1978 Metall. Trans. A9 731

Champion F A 1948 in Symposium on internal stresses in metals and alloys (London: Institute of Metals) p. 468

Dickson J I, Groulx D and Shiqiong Li 1987 Mater. Sci. Eng. 94155

Flanagan W F 1991 Acta Metall. 39695

Galvele J R 1987 Corrosion Sci. 271

Galvele J R 1990 Corrosion Sci. 30955

Hirth J P 1980 Metall. Trans. A11 861

Jani S, Marek M, Hochman R F and Meletes E I 1991 Metall. Trans. A22 1134

Jones D A 1985 Metall. Trans. A16 1133

Logan H L 1952 J. Res. Nat. Bur. Stand. 4899

Louthan M R Jr and Devrick R G 1975 Mater. Sci. 15565

Magnin T, Chieragatti R and Oltra R 1990 Acta Metall. 361313

Rhead G E 1975 Surf. Sci. 47207

Scully J C 1968 Corrosion Sci. 8513

Staehle R W 1973 Proc. of conf. on SCC and HE of iron base alloys, Firmini, France (Houston: NACE)

Staehle R W, Forty A J and Rooyen D 1969 in Fundamental aspects of stress corrosion cracking (eds) R M Latanision and R W Staehle (Houston, Texas: NACE) p. 214

Stefac R and Franz F 1978 Corrosion Sci. 18161

Tien J K. Thomson A W, Bernstein I M and Richard R J 1976 Metall. Trans. A7 821 